\title{
Prediction of Preeclampsia by Uterine Artery Doppler Examination and Placental Growth Factor, Endoglin and Pregnancy-associated Plasma Protein Levels in Maternal Serum at 11-13+6 Pregnancy Week
}

\author{
(DD Şule Yıldırım Köpük¹, (D) Yiğit Çakıroğlu², (D) Yasin Ceylan³, (D) Mustafa Baki Çekmen4, (D) Gülseren Yücesoy² \\ 1 Ümraniye Training and Research Hospital, Clinic of Obstetrics and Gynecology, Istanbul, Turkey \\ ${ }^{2}$ Kocaeli University Faculty of Medicine, Department of Obstetrics and Gynecology, Kocaeli, Turkey \\ 3 Mardin KızItepe State Hospital, Clinic of Obstetrics and Gynecology, Mardin, Turkey \\ ${ }^{4}$ Medeniyet University Faculty of Medicine, Department of Biochemistry, Istanbul, Turkey
}

\section{Abstract}

Objective: We aimed to evaluate the prediction of preeclampsia by maternal serum pregnancy-associated plasma protein A (PAPP-A), placental growth factor (PIGF), sEndoglin (sEng) and uterine artery Doppler examination.

Methods: One hundred and ninety-three singleton pregnant women admitted to outpatient clinic at 11-13+6 weeks for first trimester combined screening test were included in the study. Maternal history was taken, and uterine artery Doppler examination and serum biomarker screening (PAPP-A, PIGF, sEndoglin) were conducted. The follow-up results of pregnancy were recorded. The study cohort was divided into two groups as "control" and "preeclampsia". Mann-Whitney U and chi-square tests were used for comparison of independent variables. Sensitivity and specificity for the predictive values of the significant parameters were calculated from ROC curves.

Results: Of 193 women, 168 women (87\%) were in the control group (group 1) and 25 women (12.9\%) who developed preeclampsia were defined in the preeclampsia group. In preeclampsia group, 20 women (10.3\%) with gestational hypertension and mild preeclampsia were defined as "group 2", and five women (2.5\%) with severe preeclampsia and hemolysis, elevated liver enzymes, low platelet were defined as "group 3". Maternal serum PAPP-A, PIGF, sEng levels were not significantly different between preeclampsia group and control group, whereas uterine artery Doppler pulsatility index (PI) values were significantly higher in preeclampsia group ( $\mathrm{p}=0.023$ ). sEng levels were significantly higher in group 3 than those in group 2 ( $p=0.001$ ). If uterine artery PI cut-off level was taken as $>2.23$ in ROC curve analysis, sensitivity was $42.31 \%$ and specificity was $82.10 \%$ for detecting preeclampsia.

Conclusion: Maternal serum PAPP-A, PIGF and sEng were not effective in predicting preeclampsia. However, these markers can be used to distinguish between mild and severe preeclampsia. First trimester uterine artery Doppler examination is an effective screening method for predicting preeclampsia.

Keywords: Preeclampsia, uterine artery, pregnancy-associated plasma protein A, placental growth factor, sEndoglin

\section{INTRODUCTION}

Preeclampsia (PE) affects approximately 2\% of all pregnancies and it is the most significant cause of maternal perinatal mortality and morbidity (1). Today, early detection of PE has become one of the fundamental goals of perinatal medicine. Although clinical symptoms of PE emerge after $20^{\text {th }}$ week of gestation, trophoblast invasion that is responsible for pathogenesis occurs in the first trimester (2). High-resistant spiral arteries can be detected from the $11^{\text {th }}$ week of gestation by uterine artery (UtA) Doppler examination (3). Therefore, first trimester UtA Doppler examination may be a good noninvasive method for predicting PE that reflects abnormal trophoblast invasion. The addition of maternal history and biochemical serum markers to UtA Doppler examination is strongly associated with placental and endothelial dysfunction (4). These markers make screening relatively earlier, and most importantly, when used with first 
trimester Doppler sonography, they provide higher predictive value and more advanced diagnostic performance (5). Placental growth factor (PIGF) and vascular endothelial growth factor (VEGF) are potent angiogenic factors and they have a stimulating effect on endothelial cell proliferation and migration. Soluble fms-1ike tyrosine kinase 1 (sFlt-1) and soluble endoglin (sEng) are anti-angiogenic factors and it is suggested that hypoxic placenta secretes increased amounts of sFlt-1 and sEng $(6,7)$. Although there are contradictory results in the studies, it has been generally reported that the levels of angiogenic factors, PIGF and VEGF, are decreased in PE and the levels of anti-angiogenic factors, sFlt-1 and sEng, are increased (8). In addition, pregnancy-associated plasma protein A (PAPP-A) and free beta human chorionic gonadotropin ( $\mathrm{f}-\mathrm{BhCG}$ ) have been used for chromosomal abnormality screening tests, and they have been also investigated in the prediction of complications that emerge in advanced gestational weeks in many studies and their availability has been discussed (9). Studies have shown that especially low PAPP-A levels may be closely associated with PE (10). Prediction of PE prediction has an important role in the prevention of complications associated with PE. Based on this reality, we intended to investigate the possible relationship between the development of PE development and maternal serum PIGF, sEng, PAPP-A, f- $\beta$ hCG levels that were measured at $11+0$ and $13+6$ weeks of gestation and UtA pulsatility index (PI) values determined by Doppler ultrasonography.

\section{METHODS}

Singleton pregnant women who admitted for screening test at $11+0$ and $13+6$ weeks of gestation were included in the study. The study was planned as a prospective cohort study. Ethics committee approval was taken and cases were informed about the study. Exclusion criteria were determined as pregnancy greater than 14 weeks, multiple pregnancy, chromosomal or congenital fetal abnormality, chronic hypertension, molar pregnancy, type 1 diabetes mellitus, maternal renal disease, PE history and morbid obesity. Detailed maternal history was taken, ad nuchal translucency measurement and UtA Doppler examination were done. When consecutive similar wave patterns were obtained, PI was measured; mean PI values of right and left UtAs were calculated. Doppler measurement of the UtA PI at 11-13+6 weeks was performed by the same experienced sonographer. PAPP-A and f- $\beta$ hCG were studied from blood samples. Measurements were performed using Immulite 2000 systems autoanalyzer with Siemens kits and by chemiluminescence method. The measurements were converted to multiple of median (MoM) values. Centrifuged blood samples were stored at $-80{ }^{\circ} \mathrm{C}$ to analyze PIGF and sEng levels. After the completion of the study groups, human sEng/CD105 ELISA (Aviscera Biscience, Inc. Santa Clara, USA) and PIGF ELISA (DRG Instruments GmbH, Germany) kits were tested using micro-ELISA method by Radim Aliysei instrument in stored serum samples.

Characteristics, medical history, pregnancy outcomes, sonography findings, systolic and diastolic blood pressure values, pregnancy complications, PIGF, sEng, MoM values of PAPP-A and $\mathrm{f}-\beta \mathrm{hCG}$ of the cases were recorded in computer database. PE diagnosis was made when two different blood pressure measurements, measured every 4 hours, were 140/90 mmHg and above, and presence of $300 \mathrm{mg}$ or more protein in the urine within 24 hours or presence of $30 \mathrm{mg} / \mathrm{dL}$ (1+dipstick) protein in spot urine sample following $20^{\text {th }}$ weeks of pregnancy. According to ACOG criteria, PE group was divided into two groups as severe (group 3) and mild PE (group 2) (11). In case of only high blood pressure, gestational hypertension (GHT) was diagnosed; and in case of additional hemolysis, increase in liver enzymes and thrombocytopenia to PE-eclampsia table, hemolysis, elevated liver enzmymes, low platelet (HELLP) was diagnosed (12). Group 1 was composed of pregnant women who did not develop complications and group 2 was composed of patients with the diagnosis of PE, GHT and HELLP.

\section{Statistical Analysis}

SPSS (Statistical Package of Social Sciences) 16 evaluation version was used in the analysis of collected data. Mann-Whitney $\mathrm{U}$ test was used for statistical assessment and chi-square test was used for the comparison of classifier data. The differences between mild PE, severe PE and control group in terms of independent variables were analyzed by Kruskal Wallis test. The correlations between the variables were determined by Spearman correlation analysis. Results were evaluated at $95 \%$ confidence interval and significance was evaluated at $p<0.05$ level.

\section{RESULTS}

The study was performed on 250 pregnant women between 1641 years of age who admitted to Kocaeli University Faculty of Medicine, Department of Obstetrics and Gynecology between February 2012 and 2014. Fifty-seven cases from whom we could not get pregnancy outcomes were excluded from the study. Out of patient group including 193 cases with serum PAPP-A, $\mathrm{f}-\beta \mathrm{hCG}, \mathrm{PIGF}$ and sEng measurements performed in 11-14 weeks of gestation and with known pregnancy outcomes, 168 women were not affected by PE, whereas PE was detected in 25 women including severe PE in 4 cases, mild PE in 18 cases, GHT in 2 cases and HELLP in one case. Patients with uncomplicated pregnancy 
were classified as group $1(n=168)$, and patients diagnosed with mild PE, severe PE, GHT and HELLP were classified as group 2 $(n=25)$. None of the pregnant women included in the study had a history of smoking or pregnancy with assisted reproductive techniques in vitro fertilization. Demographic characteristics and pregnancy outcomes of the patients are given in Table 1. When preeclamptic and normotensive patients were compared based on maternal age, gravida, parity, body mass index, delivery week and values, no statistically significant difference was found $(p>0.05)$ (Table 1). There was a significant difference in terms of birth weight of the newborn, mean arterial systolic pressure

\begin{tabular}{|c|c|c|c|}
\hline Characteristics & $\begin{array}{l}\text { Group } 1 \\
\text { (control) } \\
(n=168)\end{array}$ & $\begin{array}{l}\text { Group } 2 \\
\text { (preeclamptic) } \\
(\mathrm{n}=25)\end{array}$ & p \\
\hline Maternal age (years) & $28.5 \pm 5.90$ & $30.03 \pm 6.39$ & 0.494 \\
\hline Gravida & $1.97 \pm 1.16$ & $2.10 \pm 1.03$ & 0.553 \\
\hline Parity & $1.2 \pm 0.9$ & $1.5 \pm 1.4$ & 0.600 \\
\hline $\begin{array}{l}\text { Body mass index } \\
\left(\mathrm{kg} / \mathrm{m}^{2}\right)\end{array}$ & $28.3 \pm 3.3$ & $29.3 \pm 6.7$ & 0.59 \\
\hline Delivery week & $38.06 \pm 2.88$ & $38.40 \pm 1.81$ & 0.537 \\
\hline $\begin{array}{l}\text { Weight of newborn } \\
\text { (gr) }\end{array}$ & $3080 \pm 53.51$ & $2615 \pm 189.87$ & 0.03 \\
\hline $\begin{array}{l}\text { Mean systolic blood } \\
\text { pressure }\end{array}$ & $111.15 \pm 18.14$ & $148.21 \pm 19.53$ & $<0.0001$ \\
\hline $\begin{array}{l}\text { Mean diastolic } \\
\text { blood pressure }\end{array}$ & $70.54 \pm 9.45$ & $98.05 \pm 13.18$ & $<0.0001$ \\
\hline PIGF (pg/mL) & $71.25 \pm 0.9$ & $67.24 \pm 1.1$ & 0.571 \\
\hline sEndoglin (ng/mL) & $15.38 \pm 0.2$ & $15.82 \pm 0.3$ & 0.642 \\
\hline PAPP-A (MoM) & 1.2 & 1.01 & 0.417 \\
\hline $\mathrm{f}-\beta \mathrm{hCG}(\mathrm{MoM})$ & 1.2 & 0.91 & 0.184 \\
\hline UtA-PI & $1.67 \pm 0.35$ & $1.93 \pm 0.23$ & 0.023 \\
\hline UtA-S/D & $3.76 \pm 0.2$ & $4.85 \pm 0.1$ & 0.019 \\
\hline \multicolumn{4}{|c|}{$\begin{array}{l}\text { Values are mean } \pm \text { standard deviation or } n(\%) \\
\text { PIGF: Placental growth factor, PAPP-A: Pregnancy associated plasma protein-A, } \\
\text { f- } \beta \text { hCG: Free chorionic gonadotropin, UtA-PI: Uterine artery pulsatility index } \\
\text { measurement, UtA-S/D: Uterine artery systolic diastolic ratio, MoM: Multiple of } \\
\text { median }\end{array}$} \\
\hline
\end{tabular}

and mean diastolic pressure $(p<0.05)$. There was no statistically significant difference between preeclamptic and control groups in terms of PIGF, sEng, PAPP-A, f- $\beta$ hCG serum markers. UtA PI $(p=0.023)$ and systolic diastolic $(p=0.019)$ ratio were significantly higher in the preeclamptic group. The groups are shown in Table 1.When we classified cases as control group $(n=168)$, patients who developed mild PE and GHT ( $n=20)$ (group 2), and patients who developed severe PE and HELLP $(n=5)$ (group 3), sEng level in group 3 was significantly higher than in group 2 (Table 2 ). PIGF level was relatively decreased in group 3 compared to group 2, however it was not statistically significant. PAPP-A MoM value was found to be significantly lower in group 3 compared to group 2. These results are summarized in Table 2. Prediction of PE could be made by ROC analysis with a PI cut-off value of $>2.23$, with a sensitivity of $42.31 \%$ and a specificity of $82.10 \%$. It is summarized in Table 3 and Figure 1.

\section{DISCUSSION}

Prediction of PE in the first trimester, where maximum trophoblastic invasion occurs before the onset of the disease, is definitely an important goal. Therefore, many biochemical markers that can provide an estimate of PE are still being investigated. An ideal test should be simple, rapid, cost effective and easy to use. Positive likelihood ratio should be $>15$ and negative likelihood ratio should be $<0.1$. Its sensitivity and specificity should also be high. Today, there are no tests that are sufficient for PE prediction alone or in combination. While screening test which uses maternal obstetric history is quite

Table 3. Uterine artery pulsatility index cut-off value in preeclampsia prediction

\begin{tabular}{l|l|l|l|l|l|} 
& $\begin{array}{l}\text { Cut-off } \\
\text { PI }\end{array}$ & $\begin{array}{l}\text { AUC \%95 } \\
\text { (CI) }\end{array}$ & $\begin{array}{l}\text { LR+/ } \\
\text { LR- }\end{array}$ & Specificity & Sensitivity \\
\hline Preeclampsia & $>2.23$ & $\begin{array}{l}0.639 \\
(0.566\end{array}$ & $2.36 / 0.7$ & $82.10 \%$ & $42.31 \%$ \\
& $-0.708)$ & & & \\
\hline
\end{tabular}
$\begin{aligned} & \text { PI: Pulsatility index, AUC: Area under curve, Cl: Confidence interval, LR: Likelihood } \\
& \text { ratio }\end{aligned}$

Table 2. Comparison of serum markers and uterine artery pulsatility indexes between mild preeclampsia, severe preeclampsia and control groups

\begin{tabular}{|c|c|c|c|c|}
\hline Median (25-75 p) & Group $2(n=168)$ & Group $2(n=20)$ & Group $3(n=5)$ & $\mathrm{p}$ \\
\hline $\operatorname{PIGF}(p g / m L)$ & $71.25(48.08-134.58)$ & $76.05(41.41-134.9)$ & $66.1(34.39-76.68)$ & 0.24 \\
\hline sEndoglin (pg/mL) & 1538 (1319-1732) & 1497 (1232.75-1671.75) & $1915(1804-2212.5)$ & 0.001 \\
\hline $\mathrm{f}-\beta \mathrm{hCG}$ MoM & $1.02(0.69-1.51)$ & $0.930 .55-1.33)$ & $0.74(0.52-1)$ & 0.15 \\
\hline UtA-PI & $1.67(1.34-2.07)$ & $1.84(1.5-2.55)$ & $2.07(1.86-2.71)$ & 0.023 \\
\hline
\end{tabular}

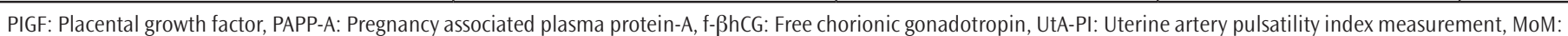
Multiple of median 


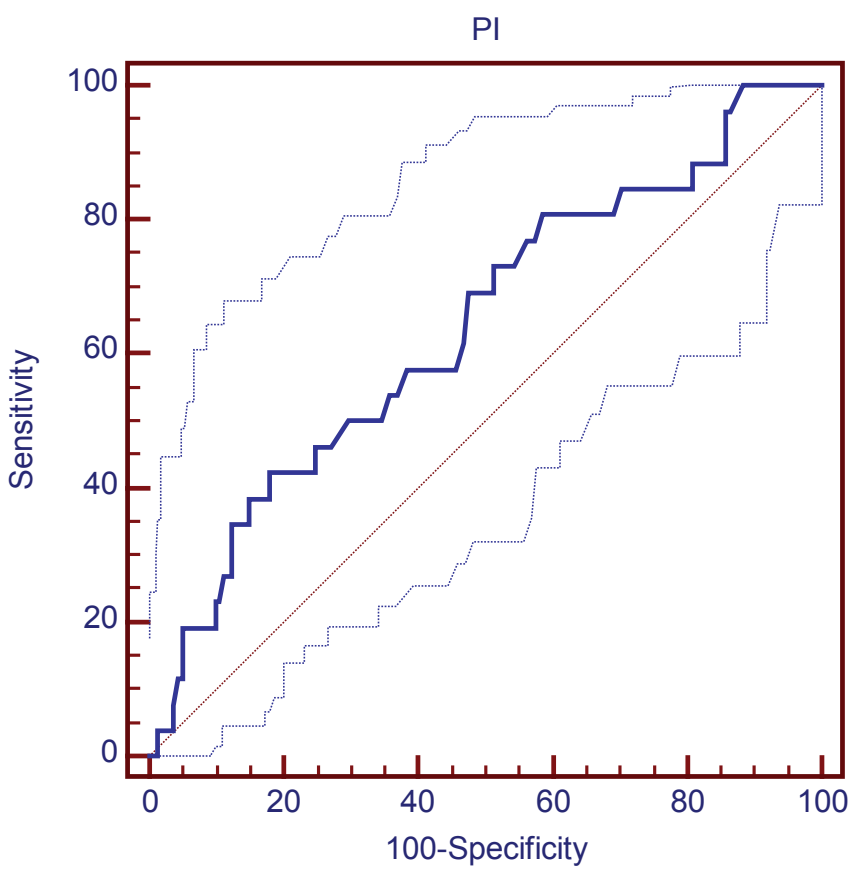

Figure 1. ROC curve analysis of uterine artery Doppler pulsatility index for prediction of preeclampsia

PI: Pulsatility index

insufficient, Harrington et al. (13) proved that PE screening might be possible by bilateral UtA Doppler examination with a high sensitivity and low specificity in the mid-1900s. In a large prospective study, the relationship between UtA Doppler findings [resistance index (RI) and diastolic notch] and the development of term and preterm PE at 11 and 14 weeks of gestation was investigated, and 57 term and 33 early PE cases were detected among 3058 pregnant women. The sensitivity of UtA Doppler examination in the detection of PE was found to be $49 \%$ within 90 percentile. In addition, it was indicated that when RI of UtA Doppler was greater than 90 percentile, there was a 6 -fold increase in the likelihood of early PE. The mean RI values of early preeclamptic women were higher compared to preeclamptic women at term (14). In a retrospective study, first and second trimester UtA Doppler indices of 3560 pregnant women were investigated within a 7-year period and PE was detected in 126 pregnant women. It was determined by ROC analysis that PI value was the best predictor of PE. The difference between mean second trimester and first trimester PI values was found to be 0.851 in PE prediction before 34 gestational weeks and 0.786 for late $\mathrm{PE}$, and the authors stated that the difference between two trimester mean PI values could be used in the prediction of PE (15). In our study, when UtA PI cut-off value was taken as $>2.23$ in the prediction of PE cases, sensitivity was $42.31 \%$ and specificity was $82.10 \%$. In recent years, new screening protocols have been introduced to the literature by Fetal Medicine Foundation with the combined evaluation of maternal characteristics, UtA Doppler and angiogenic-antiangiogenic markers (16). The addition of maternal history and biochemical serum markers to UtA Doppler examination was strongly associated with placental and endothelial dysfunction $(4,5)$. Serum PIGF, sEng, sFlt-1 and placental protein 13 (PP-13) make it possible to make screening earlier, and most importantly, when used with first trimester Doppler sonography, they provide a higher predictive value and more advanced diagnostic performance (5). While PAPP-A alone provides a prediction of $10-20 \%$ during PE screening, it can provide a prediction of $70 \%$ [ $5 \%$ false positivity rate (FPR)] when combined with UtA Doppler indices $(10,17)$. Spencer et al. (18) performed PAPP-A and PP-13 measurements in the first trimester and UtA Doppler examinations at 22-24 weeks of gestation. PAPP-A MoM value was found to be significantly lower in preeclamptic group compared to the control group. When PAPP-A was combined with UtA PI value, PE could be estimated with $76 \%$ sensitivity; however, there was no change in sensitivity with the addition of PP-13 to this combination. In their study, Di Lorenzo et al. (19) detected a significant relationship between early-onset PE and f- $\beta$ hCG value above 3.0 MoM. However, many studies retrospectively evaluating $\mathrm{f}-\beta \mathrm{hCG}$ have shown that it is unable to predict $P E(10,20)$. In a study evaluating sEng level at 1113 and 30-33 weeks of gestation, the median MoM value at 30-33 weeks of gestation was found to be higher in preeclamptic group compared to control group, and sEng level at 11-13 weeks of gestation was found to be similar between the two groups. When maternal characteristics were combined with third trimester sEng levels, late-onset PE prediction was reported as 50\% with a FPR of $10 \%$ (21). PIGF is a proangiogenic protein and PE has been associated with the production of smaller amounts of this protein. Decrease in concentration may occur during clinical symptoms and preclinical period of the disease, and it is present since first trimester. In the first trimester, preeclamptic pregnant women were found to have low PIGF concentration and it was inversely proportional to the severity of the disease (22). No difference was found between normotensive and preeclamptic patients in terms of PIGF levels tested in urine at 8-21 weeks of pregnancy. Regarding PE prediction, preterm PIGF level in the 21-32 weeks of pregnancy was higher compared to term PIGF level (23). Akolekar et al. (24) examined UtA PI, mean blood pressure, PIGF, PAPP-A values in 58.884 cases at 11-13 weeks of pregnancy. They reported a PE detection rate of $50 \%$ with a FPR of $10 \%$ by using only maternal body mass index (BMI) and mean artery pressure at 34 weeks of pregnancy and a detection rate of $75 \%$ with the addition of UtA PI and more than $95 \%$ with the addition of PIGF and PAPP-A values (24). However, Diguisto et 
al. (25) reported that the multivariate model adjusted according to laboratory and sonographic indicators had an area under the curve (AUC) estimated at 0.76 , which was not significantly different from the AUC of the univariate model adjusted only for PIGF ( $p=0.7)$. As a result, in a high-risk population, PIGF in the first trimester is useful for predicting PE, but neither sFlt1 nor any UtA Doppler indices improved the prediction of PE (25). Li et al. (26) demonstrated that UtA PI at early secondtrimester was increased in pregnancies that developed PE (1.61 \pm 0.047 vs. $1.02 \pm 0.049, p<0.001)$. In contrast, the level of PIGF was decreased in preeclamptic group compared to controls $(0.69 \pm 0.23$ vs. $1.00 \pm 0.26, p<0.001)(26)$.

UtA PI, PAPP-A, PIGF, PP-13, inhibin-A, activin-A, sEng and mean arterial pressure were studied in 33, 602 pregnant women at 1113 weeks of pregnancy. When only maternal factors (history), UtA PI, blood pressure and PAPP-A were evaluated in PE cases, early PE was estimated by $33 \%$ with a FPR of 5\%, PE between 34-37 weeks was estimated by $27.8 \%$ and PE after 37 weeks was estimated by $24.5 \%$. PE prediction rate was reported as $91 \%, 79.4 \%$ and $60.9 \%$, respectively, with the addition of other biochemical markers to maternal factors (4). In combined screening with maternal factors, mean arterial pressure, UtA PI and PLGF detection rate was 100\% [95\% confidence interval (CI) 80-100] for PE at $<32$ weeks, $75 \%$ (95\% Cl 62-85) for PE at $<37$ weeks and $43 \%$ (95\% Cl 35-50) for PE at $\geq 37$ weeks, at $10 \%$ FPR. The combination of maternal factors and biomarkers provides effective first trimester screening for preterm PE (27). Poon et al. (28) investigated 7797 singleton pregnant women at 11-13 weeks of pregnancy. The authors predicted that early-onset PE would develop in 476 patients by logistic regression analysis using variables of UtA PI, mean blood pressure, serum PAPP-A, PIGF, BMI, nulliparity and a previous history of PE in previous pregnancy; however, PE developed in 32 patients. While 7321 patients were expected not to develop PE, two patients had a diagnosis of PE. As a result, the sensitivity and specificity of this model were calculated as $94.1 \%$ and $94.3 \%$, respectively (28). In our study, when we classified the patients as group 1 (control group, $n=168$ ), group 2 (patients with mild PE and GHT; $n=20$ ) and group 3 (patients with severe PE and HELLP; $n=5$ ), median sEng value was $14.97 \mathrm{ng} / \mathrm{mL}$ in group 2 and $19.15 \mathrm{ng} / \mathrm{mL}$ in group 3 , and a statistically significant difference was detected between the groups $(p=0.001)$. sEng level in group 1 was higher than in group 2. PIGF level was relatively decreased and was $76.05 \mathrm{pg} /$ $\mathrm{mL}$ in group 2 and $66.10 \mathrm{pg} / \mathrm{mL}$ in group 3, however, there was no statistically significant difference. Similar to the literature, sEng was statistically higher and PIGF was lower between group 2 and 3. Unlike the literature, low PIGF and high sEng levels were detected in the control group. The disproportionate distribution of cases between groups $(168 / 5,168 / 20)$ and fewer preeclamptic patients may be the reason of this situation. While PIGF and PAPP-A levels decrease in PE, sEng level increases. In our study, no statistically significant difference was found between the preeclamptic group and control group in terms of these markers. We consider that this result is due to the fact that the distribution of cases was disproportionate and the number of preeclamptic cases was less than the control group. However, in subgroup analysis, it was found that PIGF level in the group 3 was significantly decreased and sEng levels were increased compared to group 2. UtA PI value was higher in preeclamptic pregnant women compared to the control group. Similar results were obtained in our study. PI value in preeclamptic group was significantly higher compared to control group $(p=0.023)$. When PI cut-off value was taken as $>2.23$ in PE prediction, the sensitivity and specificity were $42.31 \%$ and $82.10 \%$, respectively. UtA Doppler examination is an effective diagnostic tool in PE prediction.

\section{CONCLUSION}

Since UtA Doppler screening is simple and noninvasive and brings very little extra time to the duration of screening, it may be included in the current sonographic examination. The sensitivity of UtA Doppler examination may be increased by adding one or more serum markers. Combinations provide an increase in the ability of prediction and determination compared to the tests used alone.

\section{Ethics}

Ethics Committee Approval: The study was approved by the KAEK (project no: 2013/100, date: 26.03.2013).

Informed Consent: Informed consent of all patients were taken. Peer-review: External and internal peer-reviewed.

\section{Authorship Contributions}

Surgical and Medical Practices: S.Y.K., Concept: S.Y.K., G.Y., Design: Y.C., M.B.C.., G.Y., Data Collection or Processing: Ş.Y.K., Y.C., Analysis or Interpretation: Y.C.., S..Y.K., Literature Search: S..Y.K., Y.C., G.Y., Writing: S.Y.K., G.Y.

Conflict of Interest: No conflict of interest was declared by the authors.

Financial Disclosure: The authors declared that this study received no financial support. 


\section{REFERENCES}

1. ACOG Committee on Obstetric Practice. ACOG practice bulletin. Diagnosis and management of preeclampsia and eclampsia. Number 33, January 2002. American College of Obstetricians and Gynecologists. Int J Gynaecol Obstet 2002;77:67-75.

2. Caniggia I, Winter J, Lye SJ, Post M. Oxygen and placental development during the first trimester: implications for the pathophysiology of preeclampsia. Placenta 2000;21 Suppl A:25-30.

3. Gómez O, Figueras F, Martínez JM, del Río M, Palacio M, Eixarch E, et al. Sequential changes in uterine artery blood flow pattern between the first and second trimesters of gestation in relation to pregnancy outcome. Ultrasound Obstet Gynecol 2006;28:802-8.

4. Akolekar R, Syngelaki A, Sarquis R, Zvanca M, Nicolaides KH. Prediction of early, intermediate and late pre-eclampsia from maternal factors, biophysical and biochemical markers at 11-13 weeks. Prenat Diagn 2011;31:66-74.

5. Baumann MU, Bersinger NA, Surbek DV. Serum markers for predicting preeclampsia. Mol Aspects Med 2007;28:227-44.

6. Chaiworapongsa T, Romero R, Tarca AL, Kusanovic JP, Gotsch F, Mittal P, et al. A decrease in maternal plasma concentrations of SVEGFR-2 precedes the clinical diagnosis of preeclampsia. Am J Obstet Gynecol 2010;202:550.e1-10

7. Luft FC. Soluble endoglin (sEng) joins the soluble fms-like tyrosine kinase (sFlt) receptor as a preeclampsia molecule. Nephrol Dial Transplant 2006;21:3052-4

8. Al-Jameil N, Aziz Khan F, Fareed Khan M, Tabassum H. A Brief Overview of Preeclampsia. J Clin Med Res 2014;6:1-7.

9. Krantz D, Goetzl L, Simpson JL, Thom E, Zachary J, Hallahan TW, et al. Association of extreme first trimester free human chorionic gonadotropinbeta, pregnancy associated plasma protein A, and nuchal translucency with intrauterine growth restriction and other adverse pregnancy outcomes. Am J Obstet Gynecol 2004;191:1452-8.

10. Goetzinger KR, Singla A, Gerkowicz S, Dicke JM, Gray DL, Odibo AO. Predicting the risk of pre-eclampsia between 11 and 13 weeks' gestation by combining maternal characteristics and serum analytes, PAPP-A and free $\beta$-hCG. Prenat Diagn 2010;30:1138-42.

11. American College of Obstetricians and Gynecologists; Task Force on Hypertension in Pregnancy. Hypertension in pregnancy. Report of the American College of Obstetricians and Gynecologists' Task Force on Hypertension in Pregnancy. Obstet Gynecol 2013;122:1122-31.

12. Sibai BM, Ramadan MK, Chari RS, Friedman SA. Pregnancies complicated by HELLP syndrome (hemolysis, elevated liver enzymes, and low platelets): subsequent pregnancy outcome and long-term prognosis. Am J Obstet Gynecol 1995;172:125-9.

13. Harrington K, Carpenter RG, Goldfrad C, Campbell S. Transvaginal Doppler ultrasound of the uteroplacental circulation in the early prediction of pre-eclampsia and intrauterine growth retardation. Br J Obstet Gynaecol 1997;104:674-81.

14. Melchiorre K, Wormald B, Leslie K, Bhide A, Thilaganathan B. First-trimester uterine artery Doppler indices in term and preterm pre-eclampsia. Ultrasound Obstet Gynecol 2008;32:133-7.
15. Napolitano R, Melchiorre K, Arcangeli T, Dias T, Bhide A, Thilaganathan B. Screening for preeclampsia by using changes in uterine artery Doppler indices with advancing gestation. Prenat Diagn 2012;32:180-4.

16. Nicolaides KH, Bindra R, Turan OM, Chefetz I, Sammar M, Meiri H, et al. A novel approach to first-trimester screening for early pre-eclampsia combining serum PP-13 and Doppler ultrasound. Ultrasound Obstet Gynecol 2006;27:13-7.

17. Poon LC, Maiz N, Valencia C, Plasencia W, Nicolaides KH. First-trimester maternal serum pregnancy-associated plasma protein-A and pre-eclampsia. Ultrasound Obstet Gynecol 2009;33:23-33.

18. Spencer K, Cowans NJ, Chefetz I, Tal J, Meiri H. First-trimester maternal serum PP-13, PAPP-A and second-trimester uterine artery Doppler pulsatility index as markers of pre-eclampsia. Ultrasound Obstet Gynecol 2007;29:12834

19. Di Lorenzo G, Ceccarello M, Cecotti V, Ronfani L, Monasta L, Vecchi Brumatti L, et al. First trimester maternal serum PIGF, free $\beta$-hCG, PAPP-A, PP-13, uterine artery Doppler and maternal history for the prediction of preeclampsia. Placenta 2012;33:495-501.

20. Spencer K, Yu CK, Cowans NJ, Otigbah C, Nicolaides KH. Prediction of pregnancy complications by first-trimester maternal serum PAPP-A and free beta-hCG and with second-trimester uterine artery Doppler. Prenat Diagn 2005:25:949-53.

21. Lai J, Syngelaki A, Poon LC, Nucci M, Nicolaides KH. Maternal serum soluble endoglin at 30-33 weeks in the prediction of preeclampsia. Fetal Diagn Ther 2013;33:149-55

22. Kusanovic JP, Romero R, Chaiworapongsa T, Erez O, Mittal P, Vaisbuch E, et al A prospective cohort study of the value of maternal plasma concentrations of angiogenic and anti-angiogenic factors in early pregnancy and midtrimester in the identification of patients destined to develop preeclampsia. J Matern Fetal Neonatal Med 2009;22:1021-38

23. Levine RJ, Thadhani R, Qian C, Lam C, Lim KH, Yu KF, et al. Urinary placental growth factor and risk of preeclampsia. JAMA 2005;293:77-85.

24. Akolekar R, Syngelaki A, Poon L, Wright D, Nicolaides KH. Competing risks model in early screening for preeclampsia by biophysical and biochemical markers. Fetal Diagn Ther 2013;33:8-15.

25. Diguisto C, Piver E, Gouge AL, Eboue F, Vaillant CL, Maréchaud M, et al. First trimester uterine artery Doppler, sFlt-1 and PIGF to predict preeclampsia in a high-risk population. J Matern Fetal Neonatal Med 2017;30:1514-9.

26. Li L, Zheng Y, Zhu Y, Li J. Serum biomarkers combined with uterine artery Doppler in prediction of preeclampsia. Exp Ther Med 2016;12:2515-20.

27. O'Gorman N, Wright D, Poon LC, Rolnik DL, Syngelaki A, Wright A, et al Accuracy of competing-risks model in screening for pre-eclampsia by maternal factors and biomarkers at 11-13 weeks' gestation. Ultrasound Obstet Gynecol 2017;49:751-755.

28. Poon LC, Kametas NA, Maiz N, Akolekar R, Nicolaides KH. First-trimester prediction of hypertensive disorders in pregnancy. Hypertension 2009;53:812-8 